\title{
AC 2010-230: GAINING THE RESPECT OF YOUR STUDENTS: FUNDAMENTAL TIPS FOR NEW ENGINEERING TEACHERS
}

\section{John Reisel, University of Wisconsin - Milwaukee}

John R. Reisel is an Associate Professor of Mechanical Engineering at the University of

Wisconsin-Milwaukee (UWM.) He serves as Associate Director of the Center for Alternative Fuels, and co-Director of the Energy Conversion Efficiency Lab. His research efforts focus on combustion and energy utilization. Dr. Reisel was a 2005 recipient of the UWM Distinguished Undergraduate Teaching Award, the 2000 UWM-College of Engineering and Applied Science Outstanding Teaching Award, and a 1998 recipient of the SAE Ralph R. Teetor Educational Award. Dr. Reisel is a member of ASEE, ASME, the Combustion Institute, and SAE. Dr. Reisel received his B.M.E. degree from Villanova University in 1989, his M.S. degree in Mechanical Engineering from Purdue University in 1991, and his Ph.D. in Mechanical Engineering from Purdue University in 1994. 


\title{
GAINING THE RESPECT OF YOUR STUDENTS: FUNDAMENTAL TIPS FOR NEW ENGINEERING TEACHERS
}

\begin{abstract}
Most new engineering teachers enter their jobs with a strong background in research, and with high expectations placed on their research productivity. Yet, a significant portion of their job involves teaching students, often undergraduate students, in the classroom. Because of the emphasis placed on research success, new teachers often do not want to spend extra time on their teaching activities. As a result, they may struggle to become effective teachers.

Based on observations of the teaching skills and related behaviors of new engineering teachers, it is clear that most teachers usually have adequate technical knowledge of the subject, but do not have the fundamental skills needed to adequately connect with their students. This serious problem is often the result of the teacher not doing a number of simple things to gain the respect of the students. If the students do not respect the teacher, they are less likely to be motivated to do well in the course and will not pay as much attention to what the teacher is trying to convey.

Fortunately, there are many things that a teacher can do to win the respect of his or her students, and these things do not take much, if any, additional preparation time. These successful techniques which lead to respect have been formulated based on comparisons of good and struggling teachers. In this paper, these techniques are presented and explained. If implemented, these techniques should improve a new teachers' performance as the students will be more receptive to learning from the teacher and motivated to do well in the course. Again, these techniques do not require much additional time for the teacher to perform, and should produce a more positive teaching experience for the new teacher, and better learning environment and education for the students.
\end{abstract}

\section{Introduction}

Many new as well as experienced teachers of engineering, science, and technology in colleges and universities often struggle with the teaching component of their jobs. This can be very frustrating as these individuals see themselves as highly-intelligent, well-accomplished people who understand the material that they are attempting to teach to students-often undergraduate students. When the teaching struggles result in (a) poor teaching evaluations by the students or (b) a significant reduction of time spent developing his or her research program, the teaching problems can reduce the chances of the faculty member gaining tenure. So, the portion of their job that may have caused the least concern to the person before he or she was hired can result in the most stress.

There has been much research done on educational methods and many suggestions are made on how to better teach students. These are definitely important contributions, and can improve the educational environment for the student. But based on observations of new and experienced teachers in engineering, I argue that there are many fundamental things that most faculty need to do in order to become effective teachers in engineering, technology, or science. These are things 
that are so fundamental that they are often overlooked or assumed by people espousing new teaching methods. But they are things that are necessary for faculty to do to connect with their students. Other researchers have discussed some of these points, but often include suggestions that are more time-consuming than desirable for new faculty in a research environment. ${ }^{1-4}$ Kim $^{5}$ has some excellent suggestions that are echoed in this paper, but this paper provides additional suggestions. The suggested actions are things that build up the respect that students have for their teacher, and it is necessary for a teacher to have the respect of the students in order to connect with and teach their students. So as to not add further work to the faculty member, these practices require little or no additional time beyond what they should already be spending on teaching.

Below, I will review the fundamental problem faced by many faculty members, particularly new faculty members, who struggle with teaching. Following that, I will present a series of suggestions designed to build the students' respect of the teacher, which will open the door for effective teaching.

\section{The Fundamental Problem}

At most universities today, there is an expectation that faculty members will perform a significant amount of research. In addition, in engineering and science programs there is usually an expectation of this research bringing in external funding. Different schools will place different levels of emphasis on the research productivity of their faculty, but this is usually reflected in the teaching loads given to the faculty. In other words, schools with high levels of research expectations will usually give lighter teaching loads, and schools with lower research expectations will usually have higher teaching loads. This does not mean that high-level research schools do not value good teaching, but that any faculty member needs to scale the distribution of their own time to what best suits their institution.

The widespread emphasis on research has led to research often being the primary factor under consideration when hiring a new faculty member. Teaching ability and experience can influence the decision, but research is the dominant consideration for most faculty positions in most traditional engineering departments. The person most likely to be hired, therefore, is one who has excelled in research in graduate school, in a post-doctoral position, and/or in industry. Research journal articles published, conference presentations made, experience in writing research proposals (as well as securing funding), and an ability to explain one's research are often the primary determining factors in selecting a new faculty member. However, current research often requires one to be an expert in a narrow field of knowledge. The person is likely to be very intelligent and probably excelled as a student, but learned and last used some of their undergraduate course material perhaps 7-10 years before seeking a faculty job.

The fundamental problem is that this person is then placed, as a new faculty member, into a classroom and told to teach a class. The person may or may not have any experience as a teacher, and if they do have experience it may be limited to having Teaching Assistant duties. They may or may not be given a course that is a fundamental aspect of their research, but has many details that they have not given much thought to in many years. They may be given some assistance by another faculty member when starting to teach a new course, but generally are 
given no formal training unless they had sought such training on their own before beginning their faculty career. At the same time, this person is also being asked to develop a substantial research program, advise graduate students, and gain external funding. To further complicate matters, the faculty member may be given new classes to teach each semester. Within a few years, this person is expected to have become an effective teacher.

Clearly, this can be a daunting task for many faculty members. Most faculty members would like to be good teachers, but often do not have the time to devote to learning new teaching techniques, or developing new educational materials to really enhance the education provided to the students. But based on observations of other faculty and listening to the comments and concerns of students with regards to their teachers, I believe that the teaching of many faculty would be quickly improved by better connecting with the students, with the primary need in that connection being gaining the respect of the students. Faculty may want to think that their students automatically respect the teacher, and in general students will begin a course respecting a teacher. But if a teacher does not do anything to retain / earn that respect, the students will have less incentive to respect and connect with the teacher. And a teacher who does not connect with the students can not teach them, no matter how well they themselves know the material.

\section{Fundamental Practices to Gain (and Retain) the Students' Respect}

In this section, I am going to discuss some fundamental practices to either gain or retain the respect of the students. The reason for either "gaining" or "retaining" is because the amount of respect that a teacher may have at the start of a course can be affected by the students' experiences prior to taking the course. An individual teacher may be granted more or less respect based on their reputation. But the experiences had by the students from other engineering and science teachers may also play an important role. For example, it may be the norm at a certain engineering school that it takes 3 weeks for students to receive graded tests back from the teachers. Students may expect that, but may not like it and therefore may have less overall respect for the teachers than at a school where the tests are routinely returned the next class. So, a teacher in the school with the 3-week norm may gain the respect of students by returning tests the next class, but would "only" retain the respect initially there at the next-class norm school. However, retaining a high-level of respect is just as important as gaining respect when it starts at a low-level. For simplicity, I will continue in this section to refer to this just as gaining respect.

Many things can cause a teacher to lose the respect of his or her students, including not showing the students proper respect, unavailability, disorganization, tardy feedback, and inconsistent grading. Someone who wants to be a teacher is not going to start out intentionally doing such things. But, one may not realize that it is important to do the opposite in order to gain the respect of the students. Or, a teacher may become so consumed with other activities, such as research, that the fundamental practices for teaching slide to the background. Below are a number of suggestions of actions that should be done by the teacher in order to gain the respect of the students. Note, these do not require more overall time than what a faculty member should be minimally spending on teaching; the total time may need to be redistributed (such as grading a test soon after it was taken, rather than waiting 2 weeks), but not increased. 


\section{Be Available}

Most schools have policies on office hours. These are specific times that faculty set aside to be in their offices to be available to help students. Few things are more frustrating and discouraging to a student than to go to their instructor's office hours only to find no one there, and no sign saying where he or she can be found. Some students naturally gravitate towards the offices of their instructors, but others require gathering up courage to do so. So, if this happens even just once or twice, the student may give up trying to get help, and the student will question the quality of the instructor.

I am very open in my availability for seeing students in my office. I generally set aside a few hours each week when I guarantee I will be there or that I will let them know in advance and schedule a different time for that week. I also tell the students that if I am in my office, I will help them at any time, provided I am not supposed to be somewhere else in a few minutes. The students can also e-mail or phone. This type of practice can be very time-consuming, but I have never found it to be overly burdensome. Most students' questions are handled quickly. Using email can also allow you to control the flow of questions if necessary. However, it is best to set some expectations on e-mail responses; students should know that you may not answer them quickly 24 hours a day, 7 days a week. In addition, students should be made aware that e-mail questions are usually best reserved for questions of clarification, rather than for questions which require a detailed response or which lead to follow-up questions by the student.

Another factor to consider is your needed availability may vary during the semester. When the due date for a project is approaching, or when a test is near, students will often be seeking more assistance. In those cases, you should try to increase your availability, and let the students know that you will be available at additional times.

\section{Be Organized in Your Lectures and Course Materials}

When a teacher is not devoting adequate time to a course, often the first thing to suffer is the organization of the lecture material. This is something that can show up in many ways. A teacher who is teaching a course for the first or second time and is working on developing lecture notes may run out of time and find that he or she is heading towards the classroom with just a vague idea of what will be covered in the class that day. Or, that teacher may be just developing notes by writing down things from the book without thought as to how this material will be presented. Then, when the teacher is in front of the classroom he or she either realizes that they do not understand the material well enough to teach it or has some insight about the material in the middle of class that he or she then has to try to work into the lecture on the fly. In these situations, the teacher runs the real risk of having to stop in the middle of class to think through what he or she is trying to say. Furthermore, the teacher is likely to backtrack, repeat himself or herself, and present a confusing lecture for the students. Such actions will cause some students to question how much the teacher actually knows about the material.

For teachers who have taught a course several times before, it is still important to at least review the lecture material before class so that he or she knows where the lecture is going. Even if an instructor's notes are good, if he or she does not remember where the lecture is going, it is very 
possible that the teacher will emphasize the wrong points, or forget to emphasize something that is to be used later. This again requires backtracking, and correcting of the lecture, which can frustrate the students immensely.

The lectures throughout the semester should flow forward. In most classes, they should not consist of isolated concepts. And the whole semester's worth of lectures should be organized as well as the individual lectures. This requires that you work on the lectures in advance.

If you find that you are having trouble staying on track in lectures, or if your students seem confused regularly, you may want to consider preparing daily objectives for the course.

Determine these before you start organizing you lecture, and you will have a set purpose as you work. Present these at the beginning of the lecture to the students, and the students will have an understanding as to what will be covered that day, and will know what they should be taking away from the class at the end of the lecture.

Preparing organized lectures and other course materials does take time, but it is time that one needs to spend in order to have a reasonable chance of being an effective teacher. By organizing the material as early as possible, you will present a better "performance" for the students, and will gain their respect.

\section{2a. Teach the Course, Not the Textbook}

As a corollary to being organized, one should realize that you are teaching a course, and not a textbook. You should follow the general flow of the textbook, you should use consistent terms and symbols as the book, but you should not be reading from the textbook, or even covering everything that is in the textbook. You should bring in supplemental material that is not in the textbook. If all you do is essentially read the textbook, your lecture may be very organized but your students will see no reason to attend your class.

\section{2b. Do Not Read Lecture Notes}

It is perfectly acceptable to have and use lecture notes. Most college engineering and science teachers are not able to walk into a classroom without any notes, and present a flawless lecture, including example problems. To do that, you either need a great memory, or an ability to think very quickly on your feet. Therefore, most engineering and science teachers in college, particularly new teachers, will need lecture notes.

The issue is how you use the lecture notes. The first time or two that you teach a course you will probably be following your lecture notes very closely. This is logical because you have not repeated teaching the subject matter many times. You should be working towards, as you gain experience, needing to rely less and less on the notes as you teach. You should never read directly from your lecture notes, except when you are giving people an exact quote from someone, or when you have formulated an explanation perfectly and want to be sure to get it that same way for the class. 
Students do not want to see a teacher stand in the front of the classroom and stare at their notes the entire class. That is a dull presentation style, which will result in you having difficulty keeping the class interested in the material. It also gives the impression that you do not thoroughly understand the material yourself, and so the students have less confidence in you as a teacher.

\section{Be Fair and Consistent in the Treatment of the Students}

Being fair and consistent with the students is important, as how you treat one student often is relayed by that student to others in the class. If you treat one student one way, and another student another way, the students will see the inconsistency, and begin to resent it, causing a loss of respect. Being fair and consistent often means setting ground rules at the beginning of the semester, and sticking to those rules. That sounds easy, but can be a problem in a couple of ways. First, you need to figure out rules that are fair to the students. Second, you will probably find some students asking for the rules to be broken for what sound like reasonable reasons. If you care about the students, you may often wish to comply with these requests.

It will take some time to determine what ground rules work best. The thing to remember is that as long as they are not draconian in nature, your students will likely accept the rules and work with them. If you come up with unreasonable rules that unduly punish students for a small misstep, then you will encounter resistance from the students. For example, if you state that a test will end at "10:20" and insist on collecting them at that time, some students might be unhappy that they had to turn in their test in the middle of their solution, but if everyone has to turn it in, they will not hold it against you. But, if you had a rule that students need to be present for a test on time, and that you would not let anyone in to the class after the start of the test at 9:30, you will probably make an enemy out of any student who is running up to the door when you close it on them. To understand why, consider the impact. In the former case, all students had equal time to work on a test, and any unfinished work will probably only cost a few points. But in the latter, a student who is 1 minute late and who may very well have still aced the test ends up failing.

\section{Be Enthusiastic About the Subject}

Most students enter science and engineering classes without a preconceived notion about the subject matter of the course. Students will have a good idea about the subject material for a course such as "Introduction to Robotics," but how many students will have a good idea of the content of "Heat Transfer" or "Soil Mechanics"? They might understand what the title means (although even that is not always the case) but most students will not naturally be very excited about studying most of the topics in the curriculum. That does not mean that they are not interested in learning the material. It just means that they do not have a well-formed opinion of the subject, other than maybe hearing that the course is "difficult" or "easy."

That is why a teacher must be enthusiastic about the subject. If the students come to class, and the instructor rarely exhibits any excitement about the material, the students will be hard pressed to develop much of an interest in the class. And if the majority of students are not interested in 
the class and are not inspired to do well in the course and learn the material, the instructor will have difficulty gaining their respect and connecting with them.

\section{Provide Prompt Feedback}

Tests and homework should be graded promptly and returned quickly. If these are returned the next class, or even within one week, the students can learn more from the feedback, while they still have time to build off of that information. Returning graded materials quickly also demonstrates to the students that the teacher is concerned enough with the performance of the students that they wish to provide useful feedback to the students in a timely fashion, even pushing doing the grading ahead of their other responsibilities. This builds respect.

\section{Have Realistic Expectations of the Students}

Few things are more disheartening to a student at the beginning of a course than seeing that their teacher expects them to spend 10 or more hours a week on routine reading and homework, as well as work on a large project during the semester. Few things are more discouraging to a student during the semester than to find that they are given an extremely difficult exam, and then are penalized heavily for even minor mistakes. Both of these situations can result when a teacher has unrealistic expectations of what the students are capable of doing in a class.

A teacher needs to find realistic expectations for what the students in the class can handle. The quality of the students influences what can be expected of students at different schools. At some schools, students relish more challenging work, and a faster coverage of the material, while at other schools, the students can not manage such things because they have to work full-time to support themselves and their families. Having realistic expectations does not mean watering down the subject matter to a bare minimum of material, but rather matching what you expect of the students to what they can realistically be pushed to do. Excessive watering down of material will tend to reduce the respect that students have for their teachers. Similarly, students will not respect a teacher who gives out high grades to everyone, as the students who really did work hard and learned the material will not appreciate others getting the same grade and other students will figure that they do not need to do much to get a good grade from that teacher. Expect quality work, and reward quality work, but match the "quality" with a realistic definition.

\section{Show Concern for the Students}

Students want to impress their teachers. Students want to be recognized and encouraged by their instructors. And some students will do well in a class and have no particular issues no matter how well or poorly the course is taught. But most students need encouragement and help and also need to see that someone cares how they do in a class. For those students, real problems can result if they encounter a teacher who seemingly has no concern for the class, little interest in the students, and acts as though they are bothered by having to deal with the students.

If you project an image of concern and caring for the students and how they learn, the students will be encouraged to perform better. It is not at all difficult to be concerned with the students. While some teachers will go the extra mile and try to get to know every student in their classes, 
and learn about their interests, backgrounds, and aspirations, that level of interest is unnecessary for demonstrating concern for the students. Getting to know every student in the class would make a great impression, but it is not always realistic for teachers of large lecture sections who also have non-teaching responsibilities. But what you should be aiming for is to recognize that your students have other classes and other responsibilities. You should encourage your students to seek your help if they are struggling with a topic or need help in other ways. You should express genuine interest in the students and their activities, and with how they are doing in the class. These actions demonstrate your concern and gain the students' respect.

\section{Strive for Clarity in Your Speaking and Writing}

In order for the students' time in the classroom to be well spent, the students should be able to fully understand their teacher. They should be able to understand what you are saying, and what you are presenting visually (i.e., writing on the board.) Therefore, you should try to determine how easy it is for the students to understand your speaking, and how easy it is for them to decipher anything you write on the board or present on a screen.

If you have an accent, you need to work on reducing the severity of the accent and probably on speaking more slowly. Most faculty also may benefit by speaking more loudly, and by practicing their enunciation. Watch how good public speakers perform. They speak loudly and clearly. They look at their audience. They do not mumble. They do not look at the ground or away from the audience. Good public speaking takes practice, but you need to remember that you need to be a good public speaker to be effective in the classroom and command the students' attention.

Similarly, you need to be certain that any information you present visually is clear. Traditionally, this has been handwriting on a board, and in many cases still involves this. For board writing, you need to be sure your writing is legible, orderly, and large enough to be seen clearly throughout the whole room. If you use projected notes, such as through a Powerpoint presentation, be sure that the font is clear, that the foreground text is visible in front of the background, and that figures are legible. In other words, prepare the lecture as you would for a good research conference paper presentation. The more clear and more intelligible the lecture, the more respect you will gain from the students.

\section{8a. Be Dynamic}

As a corollary to having clear speaking and writing, move around in the classroom. If you are writing on a board, this is natural. But one trap that people using prepared slides can have is that they may end up standing, or worse yet sitting, in one place the entire lecture. If you are sitting down the whole lecture, reading from slides, the students will see no reason to be in class. So, move around, add things that are not on the slides, ask the students questions, and generally do things to keep the students engaged in the class. 


\section{Have Firm but Fair Grading}

Following along with the being fair and consistent with students, and with providing quick feedback, is the need to be fair in your grading. Just about the last thing you want to do is to be grading a test and take off a different number of points for the same mistake on different students' tests. Avoiding this takes diligence when you are grading a test or an assignment. What routinely happens to me is that I will see a certain mistake on say the fourth test I grade, and then ten or fifteen tests later I see the same mistake. Then I need to go back and find the test that had the mistake originally and see how many points I deducted. This can be time consuming, but really is necessary to be fair to the students. Miguel and Larson ${ }^{6}$ provide many tips on effective grading.

\section{Solve Homework and Test Problems Before Assigning or Distributing Them}

Solving problems before assigning them takes time. As a result, many busy teachers will brush this aside as being unnecessary. For homework problems, the teacher may rely on an instructor's manual for the solutions. For test questions, the teacher may either rely on a solution manual if they took the problem from another book, or they may figure that it must be solvable because it "sounds good." In some cases, the teacher may rely on a grader or TA to solve the homework problems. But a problem that is not solvable (or unexpectedly difficult) due to missing information or poor phrasing will just cause distress for the students, and push the students to respect their teacher less.

The best way to check to see if a homework problem is solvable is to sit down and solve it yourself. Reading a problem is not enough. Problems may look good when you read them, but it is usually only when you try to solve them yourself that you find that a piece of information is missing. I recall one time when a student from a different class came to my office to ask if a problem had enough information. I looked at the problem, and on the surface it sounded like a good problem. But then I started to work through a solution, and quickly found that, indeed, there was not enough information. That should have been caught by his instructor, but it was not. That student had spent quite a lot of time on the problem, and was frustrated by the situation.

\section{Find Answers to Questions that Stump You}

No matter how well you know the material that you are teaching, it is likely that you will occasionally be asked a question by a student to which you do not know the answer. In some cases, the question could be indicative that you do not really know the material that well, and you can use these questions to direct your own study of the material so that you are more prepared for teaching the material in the future. But in most cases, particularly as you gain experience teaching a subject, the questions are either a result of the student looking at the material from a different perspective, or from a student trying to learn the material at a much deeper level than you considered appropriate for the class.

If you are faced with a question that you do not know the answer to, it is best to admit that you do not know the answer and that you will go and do some research after class and let them know 
the answer the next class. Then, during the next class, tell them what you have found. This does not give the students' wrong answers, does not waste a lot of class time, and also shows the students that you are interested enough in helping them learn that you do additional work outside of class. These all will help increase the students' respect. Now, if you brush off the question, or do not ever get back with an answer, you are hurting the respect level. So be sure to return with an answer the next class.

\section{Discussion}

Are these the only factors that can help an instructor gain or keep the respect of their students? No, other things can be done but the ones discussed above are really designed to focus on fundamental activities and behaviors of the instructor. Also, while some take some time, most of the activities should not require any additional time over what is currently or should be spent on a class. Not doing the things listed above can drive the students away from the teacher and the class. And a teacher can not teach effectively if the students do not respect the teacher.

Even though the actions are not particularly time-consuming, they can be a lot for a teacher to focus on at once. If someone needed to start doing all the suggestions, and wondered which were perhaps the most critical, I would recommend looking at which suggestions are most likely to poison a teacher-student interaction the most. Along those lines, the three that are probably the most fundamental would be (1) Be Available, (2) Be Organized, and (3) Be Fair and Consistent. If a teacher looks at a course from the perspective of a student, what actions by the teacher could lower the respect that the student has for the instructor? If a student has questions but can never find the instructor for help outside of class, the student will grow frustrated quickly, and will think that the teacher does not care if the students learn the material. If a student comes to class, and the teacher is not prepared to give an intelligible, organized lecture, the student will see no reason to attend class and also think that the teacher either does not know the material himself or herself, or that they do not feel that they can be bothered with teaching a class. If a student finds that the teacher takes off large numbers of points for small mistakes on tests or homework, or if the teacher takes off different numbers of points for different students for the same mistake, the students will get angry and spend more energy fighting about grades with the instructor than trying to learn the material. So, while all activities discussed above, items (1), (2), and (3) are the items that can most quickly destroy the respect that students have for a teacher.

\section{Summary}

Most students want to learn. Most teachers want to teach well. To facilitate both, there are many advanced strategies designed to give teachers the tools they need to connect with their students and provide them with an excellent education. But most of these strategies will assume that the teachers are doing a series of fundamental things in their classes to gain and foster the respect of their students. But, based on observations of new faculty and even some experienced faculty, it has been found that there are many teachers who do not incorporate these fundamentals into their teaching, either because they are unaware of them or because they do not realize their importance. As a result, the teachers struggle to teach effectively, and the students grow frustrated with the education they receive. 
In this paper, many fundamental activities and behaviors have been given for teachers who are struggling to connect with their students and provide a good learning environment. The activities are things that all teachers should be doing, and generally do not require any significant additional time so that even teachers who are under pressure to build research programs can still do these things. These actions are designed to gain and maintain the respect of the students, which is necessary to keeping the students engaged in the course, thereby allowing for the students to learn. While the actions alone will not turn every faculty member into a great teacher, they will allow the teachers to become effective teachers. In turn, this opens the door to improving the education received by their students.

\section{Bibliography}

1. Marshall, J., and Marshall, J. "Pedagogy: Review of Best Practices," Proceedings of the 2008 ASEE American Society of Engineering Education Annual Conference \& Exposition, Pittsburgh, PA. (2008).

2. Chickering, A.W., and Gamson, Z.F. (1991). Applying the Seven Principles for Good Practice in Undergraduate Education. New Directions for Teaching and Learning. Number 47, Fall 1991. San Francisco: Jossey-Bass Inc.

3. Bennett, J.B., (2001). Teaching With Hospitality. In "Teaching Excellence". Center for Teaching, University of Southern Maine. 12, No 1, 2000-2001.

4. Ladeji-Osias, J.O. "Planning and Teaching an Undergraduate Course," Proceedings of the 2005 American Society of Engineering Education Annual Conference \& Exposition, Portland, OR. (2005).

5. Kim, D. "Successful Methods and Techniques for Effective Teaching and Class Management," Proceedings of the 2007 American Society of Engineering Education Annual Conference \& Exposition, Honolulu, HI. (2007).

6. Miguel, A., and Larson, E. "Efficient and Effective Grading of Student Work," Proceedings of the 2006 American Society of Engineering Education Annual Conference \& Exposition, Chicago, IL. (2006). 